\title{
Interactive Design and Gamification of eBooks for Mobile and Contextual Learning
}

\author{
http://dx.doi.org/10.3991/ijim.v9i3.4421
}

\author{
José Bidarra $^{1}$, Mauro Figueiredo ${ }^{2}$, Carlos Natálio ${ }^{1}$ \\ ${ }^{1}$ Open University of Portugal, Lisbon, Portugal \\ ${ }^{2}$ University of Algarve, Faro, Portugal
}

\begin{abstract}
Given the global spread of mobile platforms like iOS and Android, it is relevant to consider the potential of these devices to teach and learn. Our exploratory research was designed to evaluate the possibility of using common eBook formats to create gamebooks (gamified books) that are effective in teaching and learning. After analyzing the features available in many free or open tools, we decided to use iBooks Author to build a model of a dynamic book that may function as an educational game for "Environmental Studies", aimed at children in the 4th grade, mostly 9 to 10 year olds enrolled in Portuguese schools. This paper presents the design and features of this interactive book titled "Adventures in the Guadiana River", developed using the Apple iBook format, and especially set for the iPad retina. Because this is a proprietary format, we also built a prototype following the EPUB3 standard and developed new ways to interact with content within this universal format. Preliminary tests with our prototypes revealed very good usability and a promising pedagogical potential for the proposed models.
\end{abstract}

Index Terms-mobile learning; e-learning; multimedia; eBook; gamebook; iBooks Author; EPUB3

\section{INTRODUCTION}

We are presently witnessing a new era in which the classic "passive receiver" of the communication is apparently assuming a role as an active interlocutor, able to intervene and to express a critical opinion. This perspective takes shape if we look at various blogs and social websites, like YouTube or Facebook. We are actually talking about innovations that result in the development of a networked society, in constant interaction, where individuals take quick decisions, are globally informed, and integrate various digital media. In this context, it is wise to consider the integration of digital media and mobile devices (iPad, iPod, tablets, smartphones), allowing students to set personal goals, to manage educational content and to communicate with others in the right context [1].

It is also important to note that this is a generation of digital natives; these students are the generation of digital games and social networks. We cannot ignore that they are no longer the same students for which the education system was designed traditionally. These students grew in a new technological environment, with its own techno culture, and they will live in a more demanding, competitive and complex world. See, for example, the prospect of Heide and Stilborne [2], for whom "the technological revolution has produced a generation of students who grew up with multidimensional and interactive media sources; a generation whose expectations and world views are different from those that preceded it" (p. 27). Moreover, this is a generation that lives in a very complex world and will have to make very difficult decisions (economy, environment, social welfare, etc.). Unfortunately, school education often does not establish the bridges which allow students to develop skills to better understand this complexity [3].

With the emergence of (cloud) distributed learning technologies, students can learn in a more informal setting using mobile devices, without being confined to a room full of computers. Furthermore, teachers and educators emphasize the importance and need for "authentic learning activities", where students can work with real world problems [4]. Therefore, the development of educational activities for students that combine learning resources from the real world with those from the digital world has become an important and challenging research topic. This may be accomplished, for example, by using mobile communication and wireless technologies, which can be moved to any place, allowing for scientific experimentation, augmented reality, image collection, resource sharing, and communication with colleagues.

In the current context of mobility, we wanted to explore the possibility of integrating the typical structure of a game in a new type of electronic book (eBook) to be used in tablets. The concept is, in essence, an interactive eBook, which enables the integration of text with images, audio, video and animations. We understand that there are clear pedagogical benefits in the development of an innovation that combines a book with a game - let's call it a gamebook - with potential in various learning contexts (formal, informal or non-formal). It is this new possibility that we pursue in our investigation, evaluating the potential of the technology in terms of tools and interfaces.

The mobile learning concept is part of a societal model that assumes digital skills as vital in this second decade of the XXI century. We refer to, in particular, the ability to (1) analyze and produce digital information where and when the user wants, (2) make decisions in the context of an information society, (3) apply creative skills and innovation (technological and methodological), (4) engage in collaborative work and (5) master an operational knowledge of digital media and global communications.

This article reports on our exploratory investigation on eBook formats (EPUB and iBooks) and the creation of gamebooks that may be effective in various learning situations. Ongoing research involves the evaluation of three major components that are clearly distinguishable: (1) 
assess the potential of the current eBook technology, (2) study the role of narratives in games, and (3) determine the potential of gamebooks for certain educational applications.

\section{DESIGNING MoBILE LEARNING}

While reviewing the literature we found several definitions of mobile learning. It should be noted, for instance, the view of Sharples [5], who defines mobile learning as the learning process that is not limited to a fixed place and takes advantage of mobile computing technology. Considering the popularity of mobile devices (e.g, smartphones, tablets and laptops), we realize that most researchers in this field have adopted this definition, which we think remains valid in the second decade of this century.

Traxel [6] also defines mobile learning as learning that is supported by a portable or mobile device. This mobile device encourages learning through its ease of access to information, the ability to easily move and its ability to manage very diverse media (text, image, audio, video, animation, etc.). The integration of portable devices in the instructional model is assumed, in the opinion of this author, to be a possible way to increase the efficiency of learning. Portable devices have been used for a significant period in curriculum areas such as languages [7], [8], [9], [10], mathematics [11], social studies [12], [13], [14], and science [15], [16].

On the other hand, compared with traditional education based on textbooks, learning with eBooks, coupled with mobile devices, seems to be an increasingly attractive option; one which can trigger the interest and motivation of students. Considering that interactive eBooks may eventually have teaching potential, they can also be distracting and produce some dispersion [17], [18]. On the positive side, Glasgow [19] showed that student motivation is higher when children interact with multimedia materials, especially those children with reading difficulties. Supporting this view, Bearne [20] argues that most children today are immersed in vast multimedia experiences and are used to combining diverse resources to interact with. In a recent study, Larson [21] suggests that using digital reading devices promotes new literacy practices and extends the connections between text and other relevant learning resources. Despite these encouraging results, however, the development of multimedia tools and methodologies to improve outcomes in student learning remains an important and challenging question for authors and institutions [22].

Mobile devices such as tablets may actually promote a new way of "being in school", anytime and anywhere, so students do not have sit in front of a computer located in a room or lab [23]. As we shall see, mobile devices have unique features that interest us, namely, in terms of interaction and exploration modes in instructional processes. However, the iPad and other tablets are still relatively recent in the marketplace, so research of their use in education is relatively inconclusive [24], [25], [26], [27].

During a study conducted in 2009 , at the University of Wisconsin in Madison, we verified the existence of welldefined patterns in the use of mobile devices by students [28], explicitly that:

- mobile learning evolves around the social environment of the student (sharing podcasts, images, texts and notes), and is not linked to the classroom;

- learning activities are mainly based on online resources and on interaction with other people (often through academic work);

- collaboration networks and group work are an important aspect of mobile interaction anytime, anywhere;

- the ease of instantly publishing content online stimulates students to become researchers and authors;

- the possibility to easily capture, record and publish multimedia transforms students into producers and critics (for example, when interacting in Facebook, Twitter, Flicker or YouTube).

\section{GAMIFICATION IN MOBILE LEARNING}

Research in educational technology needs to go far beyond learning with multimedia to recognizing the role of new learning experiences; for example, one that games and simulations can reveal. The learning model which we call "ludic" - based on games - can be used in formal or informal education by well-defined age groups, and can be introduced in various scientific fields. But how do we broadly define "game"? For our educational purposes a working definition may be the one proposed by Klopfer [29], for whom a game is a goal-oriented activity, based on specific rules, which players perceive as enjoyable. In an educational context, considering that "ludic" is not usually a priority in most activities, a game may be the motivating factor that is needed in many learning resources.

Unfortunately, the production and deployment of educational games presents some difficulties, particularly:

- The high development costs and an uncertain market make investment in educational games and innovations too risky for producers;

- Institutions resist adopting innovations and do not want to make unnecessary changes and investments, including the use of new technologies for learning;

- Instructors, institutions and publishers do not (traditionally) want to replace textbooks with educational games;

- The value of specific educational technologies (games, simulations, etc..) have not been proven in many cases;

- Parents and teachers still have very negative attitudes about the use of games in the classroom;

- Games are especially suited to teach higher order skills that are not typically assessed through examinations (multitasking, decision-making, strategic vision, etc.);

- Easy access to computers and the Internet cannot be taken for granted in educational institutions (the case of many developing countries).

Gamification is a relatively new concept that has acquired considerable momentum over the last years [30], [31], [32]. It is a concept that integrates the mechanics of gaming in non-game activities to make these more effective and enjoyable. When used in the educational field, gamification seeks to integrate game dynamics and game mechanics into learning activities, for example, using 
tests, quizzes, exercises, edu-games, badges, etc., in order to increase intrinsic motivation and foster participation of students.

In this context, we can define game mechanics as the set of rules and rewards that make up game play, a satisfying and highly motivational activity, in other words, making it more challenging and engaging. The most common game mechanics [31] include:

- Points: studies at the University of Chicago show that points are fantastic motivators and can be used to reward users/students across multiple levels or dimensions of a gamified activity. In general people love to be rewarded and, when interacting with a point system, they feel like they have gained something.

- Levels: these are often defined as point thresholds, so the students (or users) can use them to indicate a higher status and have access to bonus content.

- Challenges, badges, achievements, and trophies: the introduction of goals in an activity make students (users) feel like they are working toward a goal. Normally, challenges should be configured based on specific actions and should include user/student rewards when they accomplish certain milestones with badges, achievements or trophies.

- Leader boards or "high-score table": in the context of gamification, high-score tables are used to track and display desired actions, using completion to drive valued behavior. In intrinsic motivation terms, they are one of the most important features of a game, bringing the aspiration factor to the process.

In a way, educational processes have always used gamification in learning activities by applying scores on assignments that can be considered points. Also, according to this perspective, the academic graduation may be considered a level achieved and a diploma earned is a form of granting a badge of confidence [31]. However, this gamebased system does not seem very engaging for the students; we think that perhaps education processes could be improve by adding the gaming factor through a technology that involves eBooks, as these are tools that students use and accept in their learning.

In this context, to overcome many difficulties, we wanted to explore the possibility of integrating the structure of a simple game in the last generation of eBooks. The aim is to create an electronic book that enables dynamic integration of text with images, audio, video and animations, but which may be used as a game. It is reasonable to admit that the educational system can more easily adopt an innovation like a gamebook - an interactive and ludic book - than conventional electronic games. It is this new possibility that looks interesting to study, based on the emergence of powerful mobile platforms (iPad, tablets, smartphones, etc.), but also relying on previous studies about games-based learning. In brief, we wanted to align eBooks with two learning scenarios: mobile learning and game-based learning.

Furthermore, it makes sense to consider the integration of mobile and game learning in systems managed by students, allowing them to set personal goals, manage content and communicate with each other. In practice, these Personal Learning Environments (PLEs) are made up of several components, which may include social networks, virtual worlds and authoring software, interconnecting various learning resources suitable to the pedagogical contexts and skills to be acquired by each learner. We argue that eBooks (or gamebooks), due to their characteristics and potential for interactivity, can be a much valued part of these PLEs.

\section{EBOOK AUTHORING}

At the most basic level, the eBook is an electronic book that can have a simple format, such as a text in PDF. However, there are currently more advanced standards, such as EPUB3 (universal) or iBooks 2 (Apple), that can integrate multimedia components. Ideally, an eBook should have sufficient quality for current devices with their high-resolution displays, be compatible with a wide variety of reader apps, and, if necessary, allow conversion to other formats. In actuality, however, there are more than a dozen formats that are not compatible with each other, and sometimes they do not adapt to higher resolution screens.

Over the years, teachers have often used multimedia encyclopedias and textbooks on CD, DVD, or online. Recently, however, a new generation of electronic books has emerged that can offer more interactive and dynamic learning experiences. Students of the "Playstation generation" tend to respond better to this dynamic and interactive content, due not only to its ability to display text, but also other media with hypertext links, search capacities and connections to online databases. One benefit of these eBooks for students is the possibility to select any word that they do not understand and find its definition immediately.

Another potential use refers to the capability to have several students simultaneously accessing the same book and thus sharing the same learning experience. More specifically, they can communicate and share files in the context of group work, all the while participating from different locations. The eBook can also contain tests, allowing students to self-assess their progress.

An economic advantage refers to financial aspects; currently, the cost of textbooks represents a high expense for students and their families. The introduction of electronic books contributes to reducing these costs effectively. Furthermore, the emergence of less expensive mobile devices is expected, which is currently already occurring in countries such as China and India. Altogether, the widespread use of eBooks will also benefit the environment by reducing paper consumption, bearing in mind that a device may store thousands of eBooks.

On a less positive note, despite the huge advances provided by this technology, many applications used to read eBooks currently do not possess really useful features such as the ability to highlight or otherwise mark text, bookmark or write notes. These are apparently trivial matters, but they are important for a student. In a paper book students usually highlight the most important parts and add annotations in the margins. In this way, when students read the book again, they can more readily focus on these parts.

Although there are several standards for eBooks, not all reading applications and mobile devices use the same. Thus, to reach a wide audience, it is necessary to adopt some of the most commonly used formats for reading electronic books: Adobe PDF in computers, Mobi for the 
Amazon Kindle, EPUB for the Barnes \& Noble Nook, and iBook for Apple's iPad. The Portable Document Format (PDF) is the most popular format for creating digital books and can be read by the free Adobe Reader installed on most computers. It is an open standard that enables the creation of eBooks with support to use sound, images, video, notes and bookmarks. Its main advantage is to keep the layout of the printed book within original quality on any device. However, this benefit is a major disadvantage on mobile devices, where text is sometimes difficult to handle in a PDF file because of its visualization, forcing users to increase or decrease text size in order to view the contents of the page. In other eBook formats, such as EPUB and iBook, there are no physical constraints to a fixed style and everything scales.

EPUB is a format based on open specifications, primarily written in XML and XHTML. The EPUB format is supported by a wide range of devices and platforms, including Android devices, Nook, iPhone, iPad, iPod, MobiPocket, Adobe Digital Editions, FBReader, Stanza, Sony Reader, and many other readers and applications. Of the most popular devices, the only one that does not support EPUB is the first Amazon Kindle. The EPUB specification is an open standard, allowing the creation of eBooks with sound, images and video (in its newest specification - EPUB3). This specification introduces innovative features to address structure limitations, such as: precise layouts specialized for comic books, support for MathML, support for multimedia, and introduction of notes.

The Amazon Kindle is an electronic book reader very popular in the US. Early versions used the Kindle proprietary format AZW. This is basically the Mobipocket format based on the Open eBook standard using XHTML. This specification supports images, notes and bookmarks. In late 2011, Amazon started selling the Kindle Fire along with the new file format Kindle Format 8 (KF8), which supports a subset of the features of HTML5 and CSS3. This is also a proprietary specification and expands the functionality of the earlier versions of the Kindle, in order for the Kindle Fire to support sound and video. Thus, eBooks can be created in these formats using a set of applications that convert PDF files in multiple formats such as EPUB, or MOBI for the Kindle, among others. For example, the widespread Calibre, which is a free application running on Windows, Mac OS X and Linux, offers a simple way to create digital books for multiple mobile platforms, starting with PDF or RTF files.

There are other free or open applications that support the creation of electronic books. For example, the application eCub allows the creation of simple books in EPUB or MobiPocket, from text files or XHTML. However, eCub is very limited, with no WYSIWYG capabilities. It is suitable for the production of simple eBooks with front and back pages with an image, index, a title page and it can convert content to a sound file (WAV or MP3). The $\mathrm{eCub}$ is free and is available for Windows, Mac OS $\mathrm{X}$, Linux, FreeBSD and Solaris.

Booktype is an open platform, available since 2012, which allows editing and writing of eBooks for different platforms by exporting in PDF, EPUB, MOBI, ODT and HTML. This application also exports the eBook directly to Amazon, Barnes \& Noble and iBookstore online stores, as well as to online printing sites. Digital books written with this application are immediately available in any of these platforms. When writing the eBook, the author does not need to worry about formatting, since it will automatically be formatted to work in these different platforms. Booktype also provides a set of collaborative tools for reviewers, editors, translators, designers, and authors, enabling the different participants to work collaborative in the production of an eBook. Some of the features offered by this platform include: intuitive drag-and-drop tools, chat, messages, adding images and text formatting. Booktype also maintains a history of all changes, which allows the author to compare different editions and return to a previous edition. It is even possible to use snippets (pieces of computer code). One of the disadvantages of this platform is the need for installing on a server and accessing via web browser, which requires some additional expertise.

The Firedocs eLML editor [33] can also be used to create eBooks. The eLML framework (eLesson Markup Language) is an XML platform for creating online classes using XML. It exports produced materials in SCORM, HTML, PDF and EPUB format. The main objective is to ensure that classes are modeled according to the ECLASS reference, which defines five distinct sections: Entry, Clarify, Look, Act, Self-assess, Summary. Current implementation only supports JPG, PNG, GIF and SVG images. It does not allow Java scripts and forms, so some of the functionalities as the glossary, references to labels and self-assessment tests are not available in the EPUB format.

SIGIL is an open WYSIWYG editor used by Google to create eBooks following the EPUB2 specification for Windows, OS X and Linux. This application imports, creates and edits XHTML documents and exports them into EPUB2 documents. EBooks created with SIGIL may contain text, pictures and links, but this standard does not support video or sound. It also provides multiple views of the work: book, code and a split mode. In the book view, it allows content edition in WYSIWYG mode.

Finally, we should mention the electronic books created in the iBook format from Apple. These eBooks are created with a free application - the iBooks Author tool. The format is proprietary, although based on the EPUB standard specification, with some differences in the CSS3 tags. This tool makes the process of creating eBooks very easy, by presenting a very complete set of integrated features, including: sound, image, video, dictionary, text underline, annotations, text-to-speech conversion, navigation and many widgets to enhance the interactive experience. The introduction of widgets in the iBook is an enriching experience for readers of an electronic book. iBook Author offers seven types of pre-defined widgets: (1) photo gallery, (2) video or audio media file, (3) review questions, (4) slide show; (5) interactive tagged images, to give detailed information on specific parts of an image or graph, (6) 3D models, and (7) objects created in HTML. The ease of creating widgets allows users to add any object to an interactive iBook, and there are many possibilities, from calculators, puzzles, maps, YouTube videos, among many others. Table I summarizes the characteristics of the authoring applications surveyed.

\section{A PROTOTYPE FOR THE IPAD}

In the process of creating a prototype of an electronic book, we started out with the idea of a gamebook - a book with a story that can be read sequentially or not. The main difference refers to the ability to choose different paths to 
the main characters or the unfolding of the history, as happens in games. The reader/player makes choices that affect how the story unfolds and his decisions have a significant impact on events and the final outcome. This will be the next step of our research.

Some choices may be as simple as turning right or left at the end of a road. Others may be much more difficult, requiring decisions about facts or occurrences, such as, problems arising in natural disasters, environmental pollution and climate change. In a particular story the student may be the main character - the hero of the story - or simply manipulate variables with consequences at the strategic level. Thus, not only decisions change the story, but also the sequence of choices can change the ending.

A gamebook may follow typical genres and formats of electronic games, such as puzzle, RPG, adventure, strategy, among others, where the reader will face threats, adversaries, and discover the truth behind an intricate story. Ultimately, in this project we strive to create a didactic narrative built on situations capable of providing expectation, suspense, challenge and other positive emotions. Based on the latter, it is theoretically possible to engage students in the study of a particular subject matter and obtain improved results in terms of attention, retention and understanding. In fact, the possibility and value of integrating game play in learning practices is indicated clearly by several researchers, who recognize its potential in making learning more meaningful and in assimilating new subject matter [34], [35], [36], [37], [38].

The development of a gambook prototype for the iPad is still in the early research phase. To build the model, we chose the Apple iBook format, essentially due to the vast potential for multimedia authoring with the iBooks Author tool, when compared with the current tools for the EPUB3 format (the most universal but the authoring tools are still in the early stages of development).

Within the initial exploratory stage of this research, and considering all the multimedia features and widgets available, we built a model of a dynamic book that can function also as an educational game for the curriculum of "Environmental Studies", suitable for children in the 4th grade program, with the title "Adventures in the Guadiana River" (fig. 1).

The ongoing research involves three strategic components, clearly distinguishable in our workflow:

1. Establish the potential of the technology: the most common formats and authoring tools that allow the creation of gamebooks that are effective in learning;

2. Identify the role of narratives and games: what kinds of narrative and game genres can be recreated as gamebooks for learning, and what learning activities can be prepared based on this typology.

3. Demonstrate real educational applications: according to a specific level of education, what pedagogical models can better integrate gamebooks, and in which subject areas are most effective.

In addition to a story that can be followed by reading the text consisting of a trip along the Guadiana River, there are several devices that make the development of the narrative more memorable. First of all, a basic text adapted to the target audience was illustrated with appealing images and galleries on various aspects of the river, emphasizing its environmental context. To ensure the en-
TABLE I.

FREE EBOOK AUTHORING TOOLS

\begin{tabular}{|l|c|c|c|c|c|}
\hline & eCub & Book-type & Fire-docs & Sigil & $\begin{array}{c}\text { iBooks } \\
\text { Author }\end{array}$ \\
\hline Photos & $\sqrt{ }$ & $\sqrt{ }$ & $\sqrt{ }$ & $\sqrt{ }$ & $\sqrt{ }$ \\
\hline Graphics & & & & & $\sqrt{ }$ \\
\hline Sound & & & & & $\sqrt{ }$ \\
\hline Videos & & & & & $\sqrt{ }$ \\
\hline Hyperlinks & & & $\checkmark$ & $\sqrt{ }$ & $\sqrt{ }$ \\
\hline Animation & & & & & $\sqrt{ }$ \\
\hline Search & & & & & $\sqrt{ }$ \\
\hline Dictionary & & & & & $\sqrt{ }$ \\
\hline Underline & & & & & $\sqrt{ }$ \\
\hline Markers & & & & & $\sqrt{ }$ \\
\hline Notes & & Msgs & & & \\
\hline Digital Speech & & & & & $\checkmark$ \\
\hline Feedback & & & & & $\sqrt{ }$ \\
\hline $\begin{array}{l}\text { Tests and self- } \\
\text { assessment }\end{array}$ & & & & & \\
\hline $\begin{array}{l}\text { Widgets/programs/ } \\
\text { apps }\end{array}$ & & & & & \\
\hline
\end{tabular}

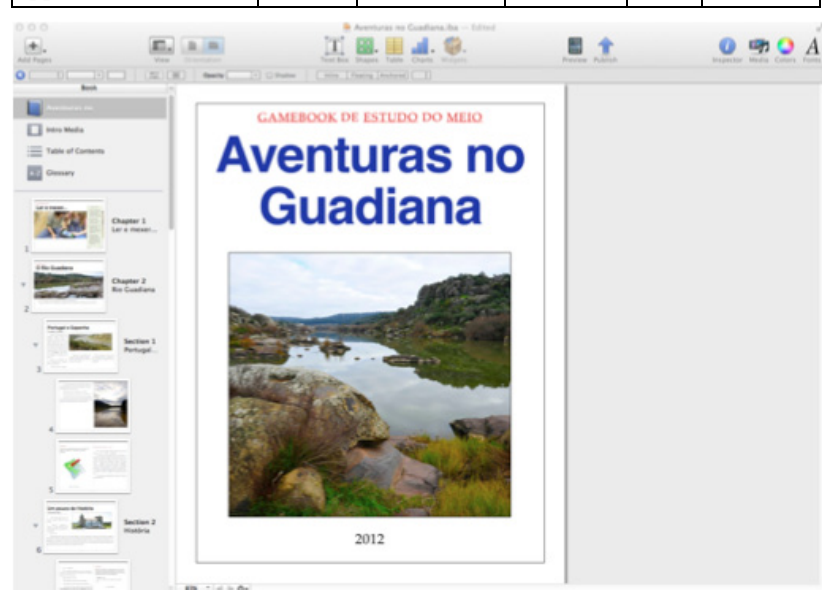

Figure 1. iBook prototype

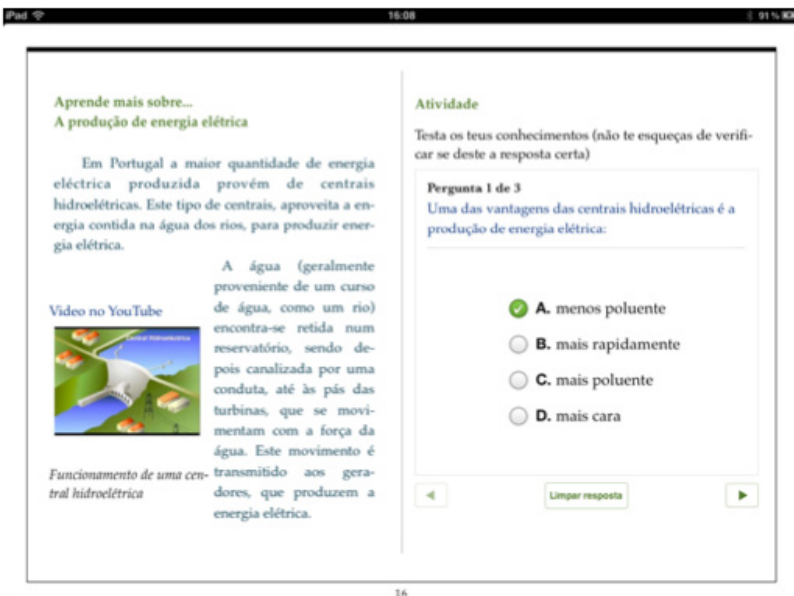

Figure 2. Video with multiple-choice questions.

gagement of readers, the narrative requires the completion of certain tasks that are supported by interactive devices based on iBooks' widgets, in particular, the inclusion of thematic videos and their exploitation through multiplechoice questions (fig. 2). To allow for geographic contex- 
tualization of themes, we opted to include Google Earth maps, accessible from a specific widget, so that the journey could be followed on the map.

We are still investigating ways to program HTML5 and new widgets so that user decisions have a significant impact on events and in final outcomes. Our ultimate goal is to allow students the possibility of selecting different paths affecting the unfolding of the story. The prototype already has a narrative based on a journey of discovery, with various unexpected situations to maintain student interest. On the other hand, while providing a suitable thematic framework, we also tested the playability of puzzle games with moving parts (fig. 3), which have the potential to motivate young users to interact more intensely with the iBook.

Initial usability tests of the model were held with a panel of a few 9 to 10 -year- old children. The first results provided very positive reactions in terms of interface usability and user motivation. However, these also show that some aspects need revision, particularly in what concerns grasping the interaction mechanisms. For example, the use of images, videos, colors and graphics seem to work well on the iPad interface, but some aspects of the widgets have to be reformulated. In the case of Google Earth, there are maps that are difficult to read or puzzles too complicated to play; technical aspects which may eventually lead to some frustration.

It was observed that students interact with a gamebook as if they were playing, when in fact they are using a tablet to learn specific content. To this end, the study continues with the development and testing of this prototype in a broader educational context, where we will use a more expanded sample, based on a class of students in the 4th year of the 1st Cycle (Basic Education). In a second phase, more robust validation tests will be made with this and other target groups, particularly covering subject areas that are traditionally unattractive to students (Math, Physics, etc.).

\section{EXPERIMENTING WITH EPUB3}

Experiments with the EPUB3 standard started with the creation of an eBook about a beautiful lagoon with a diversified fauna and flora in the middle of Portugal (Obidos). In this project, we tried many different widgets and scripts that somehow emulated the effects achieved with the Apple format iBooks. Because the EPUB3 norm does not specify what kinds of JavaScript should be used, we had to try proven solutions, based on the jQuery library that may be applied in many platforms. For instance, some scripts used in touch platforms to interact with a panoramic photo:

$$
\begin{aligned}
& <\text { script } \mathrm{src}=\text { 'scripts/jquery-1.8.3.js' } \\
& \text { type='text/javascript'></script }> \\
& <\text { script } \mathrm{src}=\text { 'scripts/jquery.ui.touch-punch.min.js' } \\
& \text { type='text/javascript'></script }> \\
& <\text { script } \mathrm{src}=\text { 'scripts/jquery.reel-1.2-bundle.js' } \\
& \text { type='text/javascript' }></ \text { script }>
\end{aligned}
$$

Another device tried was Lightbox, a technique that uses a small JavaScript library that permits users to view and increase the size of images and other content overlapping to the main page, instead of causing a new page to load (fig. 4). When the overlay is displayed, the rest of the con-
0

A Sliding Puzzle Game Stan over
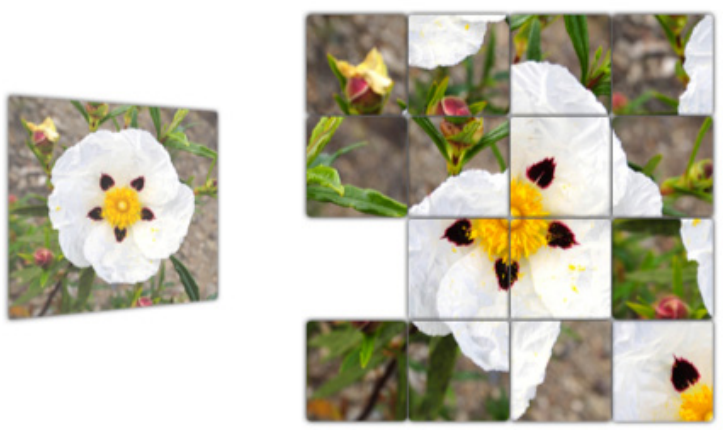

Figure 3. Puzzle game with pieces of flower (Esteva)

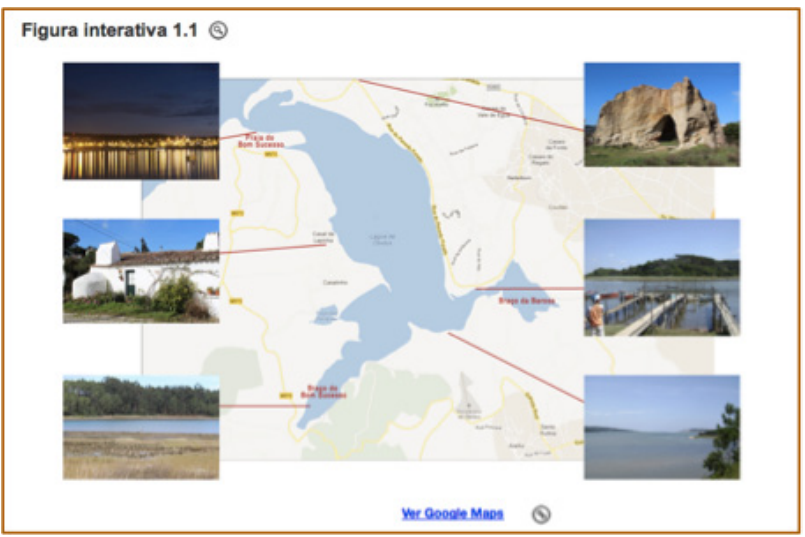

Figure 4. Page with images that expand (Lightbox).

tent of the page is dimmed for the user to focus only on the interesting part. Although the pages can be greatly expanded in tablets, one of the advantages of this plug-in is to include informational text. Depending on the settings, the overlay can be positioned, adapted to the size of the browser window on the fly. The plug-in determines which links are activated via the "href" attribute. Lokesh Dhakar wrote the plugin used:

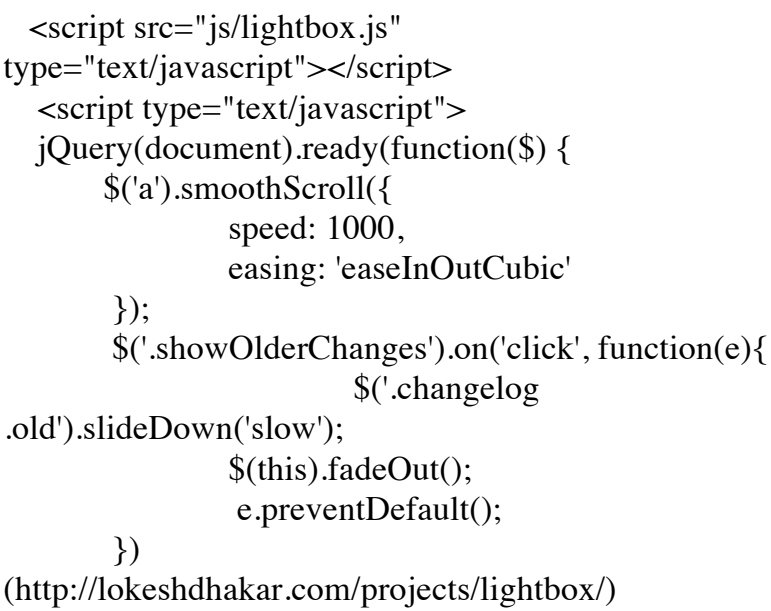

Another script used was flexslider.js, a device that creates a customized slideshow with points (fig. 5): 


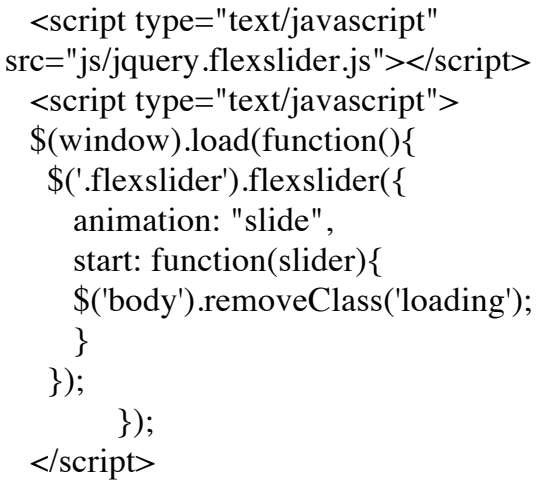

Because simple card games are appealing and easy to implement, a script called "card.js" was used because it contains a specific CSS style in the eBook for the identification of the birds in the lagoon (fig. 6):

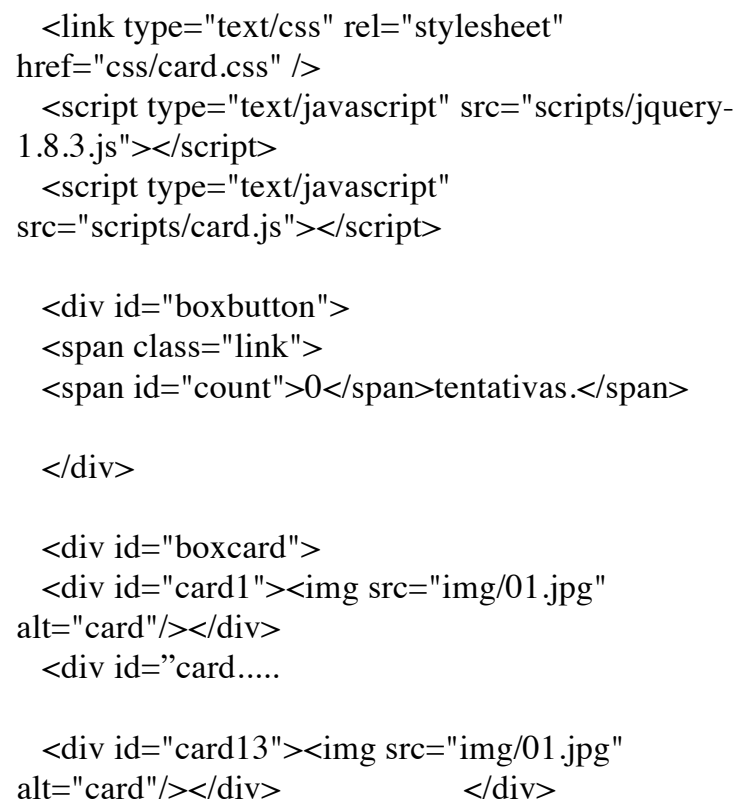

Many other scripts were tested, for example, to create a "time slider" with a historical map, to insert a "scrollbar" for a text box, to create different kinds of quizzes, and to present video and audio. One of the problems until recently, with the use of video and audio files, is that external plug-ins were needed to play videos (Flash Player, QuickTime, RealPlayer; Windows Media Player). With the advent of HTML5 and its adoption by the EPUB3 standard, this problem has been overcome. However, there are still issues relating to licenses and patents, which restrict the use of the formats. There are two main types for video coding in eBooks: MP4 for h.264 (iPad) and webm for VP8 (open format). In audio, the most common is the .MP3 format.

\section{CONCLUSION}

After studying the current state of the art in eBook technology (free and open), we chose the Apple software iBooks Author as the most suitable for the construction of our first model, mainly due to its ability to integrate sound, image, video, dictionary, text underline, annotations, text-to-speech, ease of navigation, and widgets that can enhance the interactive experience. Nevertheless,

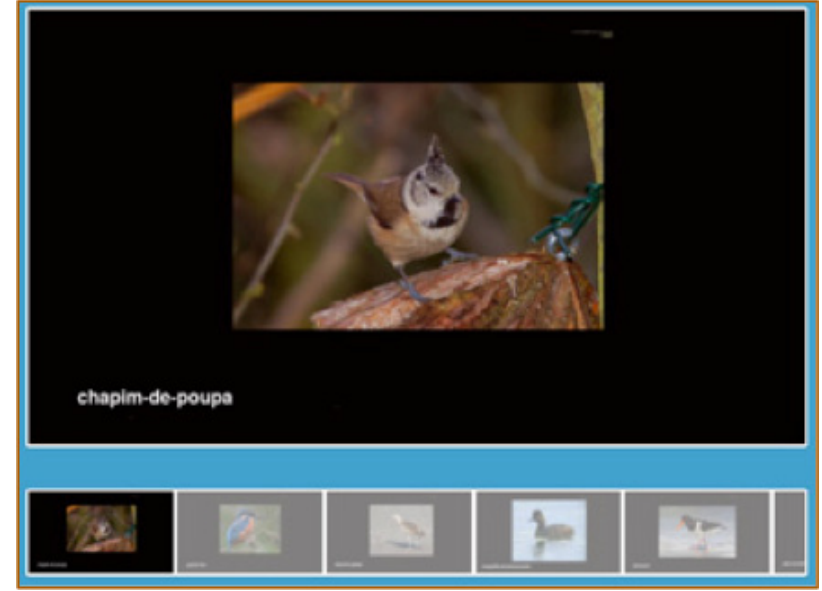

Figure 5. Page with interactive slideshow.

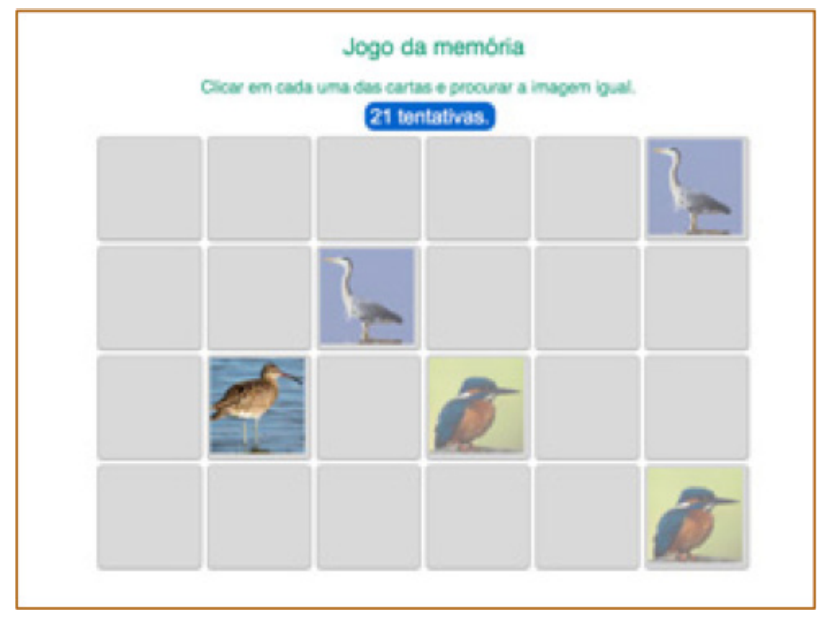

Figure 6. Card game with wild birds.

given the high cost of equipment and the limited distribution of the iPad in schools at present, the development and testing of a prototype that uses the open standard EPUB3 which may be used in any portable device (Android or iOS) was also tried. With this in mind, doctoral students are already developing new tools with EPUB3.

Preliminary tests with our prototypes suggest that the iBook technology and the EPUB3 standard have great usability and pedagogical potential for a learning eBook model. The interface and interaction design for contextual learning was the main focus. At first glance, the concept of a "gamebook" appears to have the potential to challenge students to become actively involved in the educational process, as it allows students to try different routes and distinguish what is important from what is secondary, enabling them to create and annotate material from various sources, while also encouraging the exploration of new issues. These are, however, aspects that need to be investigated and validated by future research in specific educational contexts.

\section{REFERENCES}

[1] J. Bidarra, A. M. Sousa, F. Grazina, P. Simões, P. Azevedo, "Personal Learning Environments no contexto virtual de um mestrado em Comunicação Educacional Multimédia", in M. C. Rodriguez, R. A. Silveira, P. Escudeiro (Eds), TICAI 2010, IEEE, Sociedad de Educación, Capítulos Español, Portugués y Colombiano, 2011. 
[2] A. Heide \& L. Stilborne, Guia do Professor para a Internet Completo e fácil. Porto Alegre - Brasil, Artmed Editora, 2000.

[3] J. C. Lima \& B. Silva, "TIC e processos de autoregulação da aprendizagem", in L. Almeida, B. Silva, \& S. Caires (orgs.), Atas do I Seminário Internacional "Contributos da Psicologia em Contextos Educativos”, pp. 747-759. Braga, CIEd, Universidade do Minho, 2010.

[4] J. S. Brown, A. Collins \& P. Duguid, "Situated cognition and the culture of learning", Educational Researcher, vol. 18, no.1, pp. 32-42, 1989. http://dx.doi.org/10.3102/0013189X018001032

[5] M. Sharples, "The design of personal mobile technologies for lifelong learning", Computers \& Education, vol. 34, pp. 177-193, 2000. http://dx.doi.org/10.1016/S0360-1315(99)00044-5

[6] J. Traxel, "Learning in a mobile age", International Journal of Mobile \& Blended Learning, vol. 1, no. 1, pp. 1-12, 2009. http://dx.doi.org/10.4018/jmbl.2009010101

[7] L. Bomar, "iPods as reading tools", Principal, vol. 85, no. 5, pp. 52-53, 2006.

[8] K. B. Patten \& D. V. Craig, "iPods and English-language learners: A great combination", Teacher Librarian, vol. 34, no. 5, pp. 4044, 2007.

[9] L. P. Shoemaker, "Handhelds for reading and note taking", Learning and Leading with Technology, vol. 35, no. 2, p. 36, 2007.

[10] A. Moura, Apropriação do telemóvel como ferramenta de mediação em mobile learning: estudos de caso em contexto educativo, Doutoramento em Ciências da Educação, na especialidade de Tecnologia Educativa, Instituto de Educação, Universidade do Minho, 2010.

[11] L. M. Lary, “A baker's dozen: 13 Palm applications for mathematics (and math related!) instruction", Learning and Leading with Technology, vol. 39, no. 9, pp. 22-27, 2004.

[12] A. Dixon, "Finding your way: GPS and geocaching", Learning and Leading with Technology, vol. 34, no. 8, pp. 29-31, 2007.

[13] R. Royer \& J. Royer, "What a concept! Using concept mapping on handheld computers", Learning and Leading with Technology, vol. 31, no. 5, pp. 12-16, 2004.

[14] D. L. Vess, "History to go: Why iTeach with iPods", The History Teacher, vol. 39, no. 4, pp. 479-492, 2006 http://dx.doi.org/10.2307/30037068

[15] J. Roschelle, W. R. Penuel, L. Yarnall, N. Shechtman, \& D. Tatar, "Handheld tools that "informate" assessment of student learning in science: A requirements analysis", Journal of Computer Assisted Learning, vol. 21, no. 3, pp. 190-203, 2005. http://dx.doi.org/10.1111/j.1365-2729.2005.00127.x

[16] R. Tinker, P. Horwitz, S. Bannasch, C. Staudt, \& T. Vincent, "Teacher uses of highly mobile technologies: Probes and podcasts", Educational Technology, vol. 47, no. 3, pp. 16-21, 2007.

[17] C. Burrell, \& J. Trushell, "Eye-candy" in "interactive books"-A wholesome diet?, Reading, vol. 31, no. 2, pp. 3-6, 1997.

[18] K. I. Matthew, "The impact of CD-ROM storybooks on children's reading comprehension and reading attitude", Journal of Educational Multimedia and Hypermedia, vol. 5, nos. 3-4, pp. 379-394, 1996.

[19] J. N. Glasgow, "It's my turn! Part II: Motivating young readers using CD-ROM storybooks", Learning and Leading With Technology, vol. 24, no. 4, pp. 18-22, 1996.

[20] E. Bearne, "Multimodal texts: What they are and how children use them", J. Evans (Ed.), Literacy moves on: Popular culture, new technologies, and critical literacy in the elementary classroom, pp. 13-29. Portsmouth, NH: Heinemann, 2005.

[21] L. Larson, "Digital readers: The next chapter in e-book reading and response", The Reading Teacher, vol. 64, no. 1, pp. 15-22, 2010. http://dx.doi.org/10.1598/RT.64.1.2

[22] J. Bidarra \& O. Martins, "Exploratory learning with Geodromo: An interactive cross-media experience", Journal of Research on Technology in Education (JRTE), vol. 43, no. 2, pp. 171-183, 2010. http://dx.doi.org/10.1080/15391523.2010.10782568

[23] J. Brand \& S. Kinash, "Pad-agogy: A quasi-experimental and ethnographic pilot test of the iPad in a blended mobile learning environment", Proceedings 27th Annual Conference of the Australian Society for Computers in learning in Tertiary Education (ASCILITE), Sydney, Australia, http://works.bepress.com/jeff_brand/18/, 2010.
[24] O. Murray \& N. Olcese, "Teaching and Learning with iPads, Ready or Not?", TechTrends, vol. 55, no. 6, pp. 42-48, 2011. http://dx.doi.org/10.1007/s11528-011-0540-6

[25] M. Manuguerra \& P. Petocz, "Promoting student engagement by integrating new technology into tertiary education: The role of the iPad”, Asian Social Science, vol. 7, no. 11, pp. 61-65, 2011. http://dx.doi.org/10.5539/ass.v7n11p61

[26] M. Weisberg, "Student attitudes and behaviors towards digital textbooks", Publishing Research Quarterly, vol. 27, no. 2, pp. 188-196, 2011. http://dx.doi.org/10.1007/s12109-011-9217-4

[27] B. McClanahan, K. Williams, E. Kennedy, \& S. Tate, "How use of an iPad facilitated reading improvement", TechTrends, vol. 56, no. 3, pp. 20-28, 2012. http://dx.doi.org/10.1007/s11528-012-0572-6

[28] J. Bidarra, "Emerging Digital Media, Games and Simulations: A Challenge for Open and Distance Learning", Revista de Ciências da Computação, 4, Universidade Aberta, Lisbon, 2010.

[29] E. Klopfer, Augmented Learning, The MIT Press, Cambridge, Massaschusetts, http://dx.doi.org/10.7551/mitpress/9780262113151.001.0001

[30] S. Deterding, K. O'Hara, M. Sicart, D. Dixon, \& L. Nacke, Gamification: Using Game Desing Elements in Non-Gaming Contexts. CHI 2011, pp. 7-12, Vancouver, BC, Canada, ACM, 2011.

[31] J. J. Lee \& J. Hammer. Gamification in Education: What, How, Why Bother? Adademic Exchange Quarterly, p. 146-151, 2011.

[32] K. M. Kapp, The Gamification of Learning and Instruction Game-based Methods and Strategies for Training and Education. San Francisco, Pfeiffer, 2012.

[33] R. Weibel, S. Bleisch, S. Nebiker, J. Fisler, T. Grossmann, M. Niederhuber, C. Collet \& L. Hurni, "Achieving more sustainable e-learning programs for GIScience”, Geomatica, vol. 63, pp. 109$118,2009$.

[34] M. Prensky, Digital game-based learning, McGraw Hill, New York, 2001.

[35] J. P. Gee, What video games have to teach us about learning and literacy, Palgrave Macmillan, New York, 2003.

[36] K. Squire \& H. Jenkins, "Harnessing the power of games in education", InSight, vol. 3, no. 1, pp. 7-33, 2003.

[37] J. Kirriemur \& A. McFarlane, "Literature review in games and learning", NESTA Futurelab Series, NESTA Futurelab, Bristol, 2004.

[38] S. Johnson, Everything bad is good for you: How today's popular culture is actually making us smarter, Riverhead Books, New York, 2005.

[39] J. Bidarra, M. Figueiredo \& C. Natálio, Designing eBook Interaction for Mobile and Contextual Learning, Proceedings $8^{\text {th }}$ International Conference on Interactive Mobile Communication Technologies and Learning (IMCL 2014), Thessaloniky, Greece, 2014. http://dx.doi.org/10.1109/IMCTL.2014.7011095

\section{AUTHORS}

José Bidarra has a Ph.D. in Educational Communications from Universidade Aberta (the Portuguese Open University), where he is currently Assistant Professor in the Department of Science and Technology. He is head of the Informatics, Physics and Technology Section (SIFT), and coordinator of a master degree in multimedia. His current research interests focus mainly on the application of multimedia and digital media in distance education, including eBooks, games and simulations. Many of his master and doctorate students are developing new methodologies to engage learners in effective experiences with digital media. Most of the research is conducted at Universidade Aberta and at CIAC (Center for the Arts and Communication Research, University of Algarve); other research includes a fellowship at the University of Wisconsin - Madison, USA (e-mail: jose.bidarra@uab.pt).

Mauro Figueiredo has a Ph.D. in computer science at the University of Salford, Manchester, UK. He is an adjunct professor at the University of Algarve in Portugal. $\mathrm{He}$ is member of the CIMA (Marine and Environmental 
PAPER

INTERACTIVE DESIGN AND GAMIFICATION OF EBOOKS FOR MOBILE AND CONTEXTUAL LEARNING

Research Center) and of the CIAC (Center for the Arts and Communication Research). His research interests are about the use of Information and Communication Technologies for education and, in particular, about eBooks, games and augmented reality (e-mail: mfiguei@ualg.pt).

Carlos Natálio was a research student at the Portuguese Open University and is now a researcher of eBooks, multimedia and interactive systems. He is also involved in digital authoring and corporate training on eBook design (e-mail: carlosraminhos@gmail.com).

This article is an extended and modified version of a paper presented at the International Conference of Interactive Mobile and Computer Aided Learning (IMCL2014), held in November 2014, in Thessaloniki, Greece. At that conference, it was awarded the Best Paper Award. Submitted 28 January 2015. Published as resubmitted by the authors 18 May 2015 